\title{
Supported local implementation of clinical guidelines in psychiatry: a two-year follow-up
}

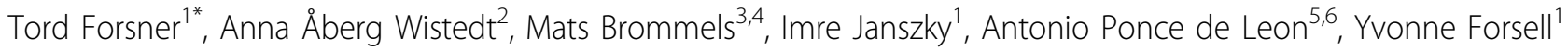

\begin{abstract}
Background: The gap between evidence-based guidelines for clinical care and their use in medical settings is well recognized and widespread. Only a few implementation studies of psychiatric guidelines have been carried out, and there is a lack of studies on their long-term effects.

The aim of this study was to measure compliance to clinical guidelines for treatment of patients with depression and patients with suicidal behaviours, two years after an actively supported implementation.

Methods: Six psychiatric clinics in Stockholm, Sweden, participated in an implementation of the guidelines. The guidelines were actively implemented at four of them, and the other two only received the guidelines and served as controls. The implementation activities included local implementation teams, seminars, regular feedback, and academic outreach visits. Compliance to guidelines was measured using quality indicators derived from the guidelines. At baseline, measurements of quality indicators, part of the guidelines, were abstracted from medical records in order to analyze the gap between clinical guidelines and current practice. On the basis of this, a series of seminars was conducted to introduce the guidelines according to local needs. Local multidisciplinary teams were established to monitor the process. Data collection took place after 6, 12, and 24 months and a total of 2,165 patient records were included in the study.
\end{abstract}

Results: The documentation of the quality indicators improved from baseline in the four clinics with an active implementation, whereas there were no changes, or a decline, in the two control clinics. The increase was recorded at six months, and persisted over 12 and 24 months.

Conclusions: Compliance to the guidelines increased after active implementation and was sustained over the twoyear follow-up. These results indicate that active local implementation of clinical guidelines involving clinicians can change behaviour and maintain compliance.

\section{Background}

Transferring research results into routine clinical practice is complicated; several studies have described implementation difficulties and the complexity of achieving performance change in health care [1,2]. Single interventions are not effective solutions [3,4]. Although knowledge about effective implementation strategies has increased their use, it has mostly only resulted in small to moderate improvements. Clinical practice guidelines are defined as 'systematically developed statements to assist practitioner and patient decisions about appropriate healthcare for specific clinical circumstances' [5]. Clinical guidelines can be used as tools [6-8], but a

\footnotetext{
* Correspondence: tord.forsner@ki.se

'Department of Public Health Sciences, Karolinska Institutet, Stockholm, SE17176 , Sweden
}

passive dissemination alone has rarely been effective in changing health care professionals' behaviour [1,9]. Guidelines have modest influence on clinical practice unless they are successfully integrated into the clinical settings [10]. Guidelines aim to influence the treatment behaviour of practitioners. However, studies are needed to show that physicians exposed to guidelines provide better treatment [11].

There is a gap between evidence-based knowledge and current practice in many medical areas $[9,12]$, and how best to implement guidelines into routine care remains unclear [13]. Implementation of guidelines mostly entails complex interventions, and effective interventions are often elaborated in complicated procedures $[14,15]$. Commonly evaluated multifaceted implementation

\section{Biomed Central}


strategies are audits and feedback, reminders, and educational outreach [2].

Successful implementation is not enough; there is also a need for continuous follow-up both of compliance to the guidelines and whether it is maintained over time. There are numerous studies showing that compliance returned to baseline after implementation of clinical guidelines [16]. So far, little has been accomplished regarding strategies for maintaining compliance. Objective measures are needed, e.g., quality indicators. Ideally, these should be derived from clinical guidelines that are based on scientific research or consensus among experts. These indicators should be measures of process and thus also measure quality of care [17]. Numerous indicators have been developed to evaluate and assess the care provided to patients with chronic physical illnesses [18], but there is lack of studies of care provided to patients with psychiatric disorders [19]. In addition, we have not found long-term follow-up studies in psychiatry on whether changes in practice after guidelines' implementation are sustained.

This study aimed to assess the effects at 12 and 24 months of an implementation intervention designed to improve documentation of quality indicators in accordance with clinical guidelines for treatment of depression and suicidal behaviour in patients at six clinics in Stockholm, Sweden.

\section{Methods}

Implementation of psychiatric guidelines in Stockholm

In Stockholm county, Sweden, a series of regional clinical guidelines regarding psychiatric disorders has been published and disseminated since 2002 [20,21]. Providers and purchasers in collaboration with Stockholm Medical Advisory Board run the development work. The intention is to require the clinical guidelines to be implemented in all psychiatric clinics in the county in order to provide high quality care on equal terms for all of the county's citizens [20,21]. A pilot study has been conducted on the implementation of clinical guidelines in the care of depression and suicide. Quality indicators derived from the clinical guidelines were used to study compliance. Our previous study showed that the indicators were feasible for audit and feedback as part of the implementation strategy, and a six-month follow-up showed favourable changes in clinical practice [22].

\section{Settings and participating clinics}

In the present study, clinical guidelines for assessment and treatment of depression and guidelines for assessment and treatment of patient with suicidal behaviours were implemented in six psychiatric clinics in Stockholm, Sweden. In Stockholm, treatment is provided almost exclusively by clinics in the public sector. All six psychiatric departments in Stockholm County were invited to implement the guidelines, and four departments decided to participate. Six general psychiatric clinics for adults were included; all were outpatient clinics in an urban area. The resources and organization were comparable. The two departments that declined participation did not differ from the ones that accepted participation in terms of organization of care, personnel resources, and population, as they had uniform contracts with the county council purchasing office. Six clinics in the four departments were randomly selected, and they were randomly assigned to an intervention group or a control group. Two of these clinics participated in implementing the clinical guidelines for depression, and two clinics in implementing the clinical guidelines for suicidal behaviours. Two clinics received the guidelines, but were not included in the intervention and acted as controls.

\section{Implementation process at the intervention clinics}

The study began in May 2003. The first author and an external psychiatrist supported the implementation process during the first six months. Local multidisciplinary teams, co-led by the external psychiatrist, including nurses, physicians, counsellors, and psychologists were established at each of the four active clinics. The teams were locally elected and participation in the local implementation work and meetings was voluntary. The first author presented the implementation study and the quality indicators for each team.

Implementation started with a baseline collection of quality indicators from medical records in order to analyze the gap between clinical guidelines and current local practice. On the basis of this, a series of seminars was conducted to introduce the guidelines according to the identified needs. The implementation teams learned to use strategies for improvements, e.g., following a cyclical process of change (plan-do-study-act model) approach [23], which was used to change local practices. Regular meetings then took place and the leaders of the teams promoted the value of implementation activities regarding patient sessions and clinical behaviour. At the meetings, all members of staff were involved in setting local goals for implementation based on the quality indicators. They were also encouraged to provide feedback and identify potential barriers and promoters to change. Feedback was given every month, based on the indicator scores, in order to ensure that improvements were gradually achieved and maintained. Local workshops at the clinics were conducted weekly during the study period, in which participants met to exchange useful approaches.

The active implementation strategies were based on organizational learning theory and previous knowledge 
of effective measures to change clinical practice. A learning organisation is described as a process of increasing the capacity for effective organisational action through knowledge and understanding [24]. Through the learning of individuals, the organisational routines are changed. One member of the research team (first author) performed site visits (academic outreach detailing) every month to the intervention clinics during the implementation period. Regular discussions of 'best practice' were held. Through facilitation, practitioners were helped to formulate and reflect on their practical knowledge and professional behaviour. Members of the local implementation teams participated twice in a regional network in order to enhance effective implementation strategies and experience during the study. The participants were encouraged to contact others in the network to exchange experiences and inspiration in the implementation work. During implementation, the adaptation of care defined by clinical guidelines was conducted by the implementation teams. A protocol for local use was developed to promote the adaptation of best practice, based on the clinical guidelines. A summary of the performed interventions is presented in Figure 1.

\section{Data collection}

The data collection took place before the start of the study, and after 6, 12, and 24 months. Patient records from adult men and women with an ICD-10 or DSM-IV diagnosis of depression were eligible for inclusion in the study on the implementation of the clinical guidelines for depression. For the implementation of the clinical guidelines for suicide attempters, the inclusion criteria were patient records from adult men and women appraised at psychiatric emergency clinics after a suicide attempt. The first 120 medical records that fulfilled the inclusion criteria from specific dates were randomly selected from each clinic, identified through the administration system. This was repeated at 6, 12, and 24 months. For the data collection before implementation, 60 to 61 records were collected from each clinic. At the control clinics, 120 medical records were selected before implementation and 120 records at each data collection point during the follow-up period. Trained abstractors examined the medical records. Inter-rater reliability was assessed by a random replicate sample of 40 records. (Kappa 0.92 to 1.0 ). The study was approved by The Central Ethical Review Board at Karolinska Institutet.

\section{Study population}

A total of 2,165 patient records were included in the systematic assessment. The study of the implementation of the clinical guidelines for depression included 1,083 adult patients, mean age 36.3 years (SD 11.2) diagnosed with a depression according to ICD-10 or DSM-IV $[25,26]$. There were no differences between the implementation and control clinics regarding gender and age distribution of the included patients. The study of the implementation of the clinical guidelines for suicidal behaviours included 1,082 adult patients, mean age 35.1 years (SD 14.7) At baseline, the mean age of the patients at the implementation clinics was lower (32.5 (12.2), versus $38.3(15.2), \mathrm{t}=2.8, \mathrm{p}<0.01)$ but there were no gender differences. At six months, there were no age or gender differences.

At 12 and 24 months there were more females and younger patients at the implementation clinics $(74.6 \%$ versus $64.2 \%$, Chi-square $=4.2, \mathrm{p}<0.1)$ (mean age 33.7 (13.2) versus 40.4(19.0), $\mathrm{t}=3.9, \mathrm{p}<0.001)$, (70.0\% versus $52.5 \%$, Chi-square $=10.7, \mathrm{p}<0.001)($ mean age 33.3 (13.4) versus 37.8(16.7), $\mathrm{t}=2.7, \mathrm{p}<0.01)$.

\section{Selection of quality indicators}

Process indicators extracted from the clinical guidelines were used as indicators of compliance. A modified audit instrument by Gardulf and Nordström [27] was used to assess the presence of the quality indicators. Each indicator was rated on a assessment scale from zero to two. The presence of the quality indicators in the medical records was given a score from zero to two, (zero, recommended criteria to guidelines were not met; one, recommended criteria were partially met according to the definition; and two, a clear occurrence). In a subsequent analyses, we used the quality indicators a binary variables where one and two (i.e., partial or full adjustment to the recommendation) were compared to zero ( $i$. $e$., no adjustment to the recommendation). As a sensitivity analysis, quality indicators were also categorised as two versus zero and one. We have found essentially similar results with this alternative approach (data not shown). For all indicators, higher scores were desirable and indicated a better compliance to the guidelines. The indicators also were summarised to a total score for each clinical guideline. The total score for the guidelines for treatment of depression was 22 points and 26 points for the guidelines for suicidal behaviour. Special recording forms were developed for the data collection. Quality indicators for implementation of the clinical guidelines for the care of persons affected by depression and clinical guidelines for suicidal patients are listed in Table 1.

\section{Statistical analysis}

The data were analysed using STATA and SPSS for Windows, versions 10 and 16.0, respectively. Inter-rater reliability was analysed by calculating Cohen's Kappa. Differences regarding age and gender distribution of the included patient records at implementation and control 
- Local implementation teams were established and were encouraged to set goals and to develop implementations plans.

- Documentation of quality indicators was used initially as objective data to identify deviance to the guidelines and local needs of training.

- Planned action and intervention based on the needs (based on local data).

- The local implementation teams held regular meetings with all staff and encouraged feedback and identification of potential barriers and promoters of change.

- Team and network meetings were performed to learn about successful implementations techniques.

- Academic outreach detailing was used to facilitate individuals and teams to analyse, reflect and change their own attitudes and behaviours.

Figure $1 \mathrm{~A}$ summary of the performed implementation interventions.

clinics were analysed using chi-square test and T-tests. To address the nested structure of our data, we fitted random-effects logit models where we clustered patients within their health care providers using 'xtlogit' command in STATA [28]. Odds ratios were calculated for the dichotomized quality indicators comparing quality of care before (reference category) and after 6, 12, and 24 months, respectively.

\section{Results}

Compliance to the clinical guidelines for depression

Table 2 shows compliance at baseline, and 6, 12, and 24 months after implementation of clinical guidelines for depression, based on the quality indicators. The documentation of the quality indicators improved from the baseline in the four clinics where implementation was carried out, whereas there were no changes, or a decline, in the documentation of most quality indicators in those without implementation. For most of the quality indicators, the increase was recorded at six months and persisted over 12 and 24 months. Although, for a few quality indicators the 24-month follow-up audit showed a slight decrease compare to the measurement at 12 months.

The compliance for some indicators was low initially and after implementation showed considerable improvement, e.g., the compliance for structured suicide assessment rose from $40.2 \%$ (for a clear occurrence to guidelines) before implementation to at least $97.5 \%$ after (Table 2). Total score of the quality indicators for clinical guidelines for depression with $95 \%$ confidence interval are presented in Figure 2.

Compliance to the clinical guidelines for the management of suicide attempters

A similar pattern was seen in the documentation of the quality indicators in the clinics that implemented the clinical guidelines for suicide attempters. There was an increase of the documentation at six months, and the increase persisted over 12 and 24 months (Table 3). 
Table 1 Quality indicators for evaluation of quality of care in depression treatment and care after a suicide attempt.

\begin{tabular}{ll}
\hline Indicator & Definition \\
\hline $\begin{array}{l}\text { Accessibility/wait } \\
\text { time }\end{array}$ & $\begin{array}{l}\text { The time between referral and actual contact with mental health } \\
\text { service }\end{array}$ \\
$\begin{array}{ll}\text { Diagnostic } \\
\text { assessment }\end{array}$ & $\begin{array}{l}\text { Documentation of present depression symptoms. The medical } \\
\text { record should document at least three of nine DSM-IV target } \\
\text { symptoms for major depression. } \\
\text { Standardized } \\
\text { rating scale }\end{array}$ \\
$\begin{array}{l}\text { Clinical depression assessment that includes a standardized } \\
\text { rating scale. }\end{array}$
\end{tabular}

\section{Requirements}

Patients receive an assessment from a mental health specialist within three weeks of their first visit to the outpatient clinic. Patients with depression and suicidal thoughts offered first contact (appointment) within 24 hours.

Depression symptoms (such as decreased socialization, sleep disorders, poor appetite according DSM-IV) noted in the medical record.

Monitoring signs and symptoms of depression using a validated standardized rating scale at the first visit. Scale and total sum documented in the medical record. Suggestions of scales to be used were presented in the guidelines.

\begin{tabular}{|c|c|}
\hline $\begin{array}{l}\text { Diagnostic } \\
\text { instrument }\end{array}$ & Diagnostic structured interview \\
\hline $\begin{array}{l}\text { Standardized } \\
\text { rating scale during } \\
\text { treatment }\end{array}$ & $\begin{array}{l}\text { Standardized rating scale during treatment for assessment of } \\
\text { symptoms and behaviour. }\end{array}$ \\
\hline
\end{tabular}

A semi-structured diagnostic interview e.g., SCID or M.I.N.I performed. Completed before the third visit.

Standardized rating scale performed within two weeks. Monitoring signs and symptoms of depression using standardized rating scale during treatment. Adjusted interventions if signs and symptoms are still present, presented in the guidelines.

Substance, drug Screening for substance use disorder. abuse

$\begin{array}{ll}\begin{array}{l}\text { Treatment plan } \\ \text { (care plan) }\end{array} & \begin{array}{l}\text { A written treatment plan documented and individually tailored } \\ \text { for the patient } \\ \begin{array}{l}\text { Evaluation/ } \\ \text { Outcome }\end{array} \\ \text { Has patient responded to antidepressant? Achieved symptom } \\ \text { remission or reduction between admission and follow-up? }\end{array} \\ \text { Sontinuity } & \text { Ability to provide uninterrupted care over time. } \\ \text { Suicide assessment } & \begin{array}{l}\text { A structured assessment documented in the medical record } \\ \text { using standardized rating scale. }\end{array}\end{array}$

Antidepressant medication

Specialist assessment after suicide attempt

Suicide assessment A structured assessment documented in the medical record

A structured assessment document
using standardized rating scales.

Current treatment with an antidepressant medication for patients with major depressive disorder, moderate or severe.

Assessment by a senior physician within 24 hours after a suicide attempt

Follow-up Care plan formulated and documented.

Evaluation Documented assessment after discharge.
Asked for current substance use and evaluated for the presence and/or history of substance use disorder. Screenings instruments such as AUDIT. Motivation interview conducted e.g., CAGE method.

The treatment plan should include; treatment, goals, time for evaluation and drawn up together with the patient.

Documented response to treatment within expected treatment frame and monitored progress. Completed a comprehensive evaluation of symptoms.

Continuity offered to the patient, same caregiver during treatment. Defined as less than two different caregivers. Identified suicidal thoughts, plans and symptoms, documented and evaluated in the medical record. Re-screen and assessment performed at every visit and documented in the medical record.

Begin appropriate antidepressant medication according the guidelines. Started within two visits.

A senior mental health specialist has made the assessment within 24 hours.

Identified suicidal thoughts, plans and symptoms, documented and evaluated in the medical record. Depression assessment conducted using standardized rating scale.

Documented discharge plans. Referral to a psychiatric outpatient clinic within one week after assessment or discharge. Telephone contact with patient during this period.
Should have a follow-up visit with a mental health specialist
Some indicators were more sensitive to change, e.g., structured suicide assessment for suicidal patients rose from $55.4 \%$ to $97.1 \%$ for a partial or clear occurrence of guidelines and specialist assessment rose from $50.4 \%$ to $91.7 \%$. Figure 2 shows the total score of the quality indicators for clinical guidelines for suicidal behaviours with a $95 \%$ confidence interval.

\section{Discussion}

This paper describes an actively supported implementation of clinical guidelines in psychiatric settings and examined compliance before implementation and after 6,12 , and 24 months using quality indicators as measurements. The results showed that there was a consistent significant increase in the documentation of almost all of the quality indicators, that this occurred after a rather short period of time, and was sustained at almost the same level throughout the two-year study period. The increase was only observed in the intervention clinics and not at the clinics to which the guidelines were only disseminated. These findings imply that a systematic implementation approach gives sustainable 
Table 2 The compliance before, 6, 12, and 24 months after the implementation of clinical guidelines for depression in $\%$ (n).

\begin{tabular}{|c|c|c|c|c|}
\hline \multirow[b]{2}{*}{ Indicator } & \multicolumn{2}{|c|}{ Implementation clinics } & \multicolumn{2}{|c|}{ Control clinics } \\
\hline & $\%(n)$ & OR $(95 \% \mathrm{Cl})$ & $\%(n)$ & OR $(95 \% \mathrm{Cl})$ \\
\hline \multicolumn{5}{|c|}{ Accessibility/wait time } \\
\hline 0 months & $77.9(95)$ & reference & $59.0(36)$ & reference \\
\hline 6 months & $89.2(107)$ & $2.4(1.1-5.2)$ & $53.3(32)$ & $0.6(0.3-1.4)$ \\
\hline 12 months & $97.1(233)$ & $13.4(5.3-34.0)$ & $44.2(53)$ & $0.4(0.2-0.9)$ \\
\hline 24 months & $90.0(216)$ & $2.5(1.3-4.9)$ & $51.7(62)$ & $0.6(0.3-1.2)$ \\
\hline \multicolumn{5}{|c|}{ Diagnostic assessment } \\
\hline 0 months & $83.6(102)$ & reference & $88.5(54)$ & reference \\
\hline 6 months & $97.5(117)$ & $9.6(2.5-36.1)$ & $90.0(54)$ & $1.1(0.4-3.6)$ \\
\hline 12 months & $97.5(234)$ & $11.1(4.0-30.9)$ & $83.3(100)$ & $0.6(0.3-1.6)$ \\
\hline 24 months & $97.9(235)$ & $10.9(3.7-32.4)$ & $79.2(95)$ & $0.5(0.2-1.2)$ \\
\hline \multicolumn{5}{|c|}{ Diagnostic instrument } \\
\hline 0 months & $12.3(15)$ & reference & $1.6(1)$ & reference \\
\hline 6 months & $28.3(34)$ & $2.8(1.4-5.5)$ & 0 & na \\
\hline 12 months & $41.3(99)$ & $5.3(2.9-9.7)$ & $0.8(1)$ & na \\
\hline 24 months & $44.2(106)$ & $5.7(3.1-10.5)$ & $0.8(1)$ & na \\
\hline \multicolumn{5}{|c|}{ Standardized rating scale } \\
\hline 0 months & $64.8(79)$ & reference & $44.3(27)$ & reference \\
\hline 6 months & $91.7(110)$ & $6.2(2.9-13.3)$ & $33.3(20)$ & $0.7(0.3-1.4)$ \\
\hline 12 months & $95.0(228)$ & $11.1(5.5-22.3)$ & $37.5(45)$ & $0.8(0.4-1.5)$ \\
\hline 24 months & $94.2(226)$ & $9.1(4.7-17.6)$ & $36.7(44)$ & $0.7(0.4-1.4)$ \\
\hline \multicolumn{5}{|c|}{ Standardized rating scale during treatment } \\
\hline 0 months & $50.0(61)$ & reference & $24.6(15)$ & reference \\
\hline 6 months & $87.5(105)$ & $7.6(3.9-14.9)$ & $38.3(23)$ & $1.9(0.8-4.2)$ \\
\hline 12 months & $97.5(234)$ & $47.5(19.0-118.2)$ & $30.8(37)$ & $1.4(0.7-2.8)$ \\
\hline 24 months & $88.3(212)$ & $8.1(4.7-14.3)$ & $33.3(40)$ & $1.5(0.8-3.1)$ \\
\hline \multicolumn{5}{|c|}{ Substance/drug abuse } \\
\hline 0 months & $46.7(57)$ & reference & $32.8(20)$ & reference \\
\hline 6 months & $87.5(105)$ & $8.0(4.2-15.4)$ & $53.2(32)$ & $2.8(1.3-6.2)$ \\
\hline 12 months & $94.2(226)$ & $18.5(9.7-35.4)$ & $35.0(42)$ & $1.2(0.6-2.3)$ \\
\hline 24 months & $88.8(213)$ & $9.1(5.3-15.6)$ & $43.3(52)$ & $1.8(0.9-3.6)$ \\
\hline \multicolumn{5}{|c|}{ Treatment (care) plan } \\
\hline 0 months & $59.8(73)$ & reference & $42.6(26)$ & reference \\
\hline 6 months & $87.5(105)$ & $5.5(2.7-11.1)$ & $38.3(23)$ & $0.9(0.4-1.9)$ \\
\hline 12 months & $90.4(217)$ & $8.4(4.5-15.5)$ & $34.2(41)$ & $0.7(0.4-1.4)$ \\
\hline 24 months & $91.3(219)$ & $8.1(4.3-15.0)$ & $27.5(33)$ & $0.5(0.3-1.0)$ \\
\hline \multicolumn{5}{|c|}{ Evaluation/outcome } \\
\hline 0 months & $66.4(81)$ & reference & $59.0(36)$ & reference \\
\hline 6 months & $95.8(115)$ & $11.9(4.5-31.7)$ & $55.0(33)$ & $0.8(0.4-1.7)$ \\
\hline 12 months & $97.5(234)$ & $20.3(8.2-49.9)$ & $48.3(58)$ & $0.6(0.3-1.1)$ \\
\hline 24 months & $95.8(230)$ & $11.9(5.7-25.0)$ & $48.3(58)$ & $0.6(0.3-1.1)$ \\
\hline \multicolumn{5}{|l|}{ Continuity } \\
\hline 0 months & $77.0(94)$ & reference & $78.7(48)$ & reference \\
\hline 6 months & $95.0(114)$ & $5.6(2.2-14.1)$ & $61.7(37)$ & $0.4(0.2-1.1)$ \\
\hline 12 months & $99.6(239)$ & $72.0(9.7-537.4)$ & $71.7(86)$ & $0.7(0.3-1.5)$ \\
\hline 24 months & $95.8(230)$ & $6.7(3.1-14.4)$ & $68.3(82)$ & $0.6(0.3-1.4)$ \\
\hline \multicolumn{5}{|c|}{ Suicide assessment } \\
\hline 0 months & $40.2(49)$ & reference & $45.9(28)$ & reference \\
\hline 6 months & $95.8(115)$ & $36.1(13.5-96.5)$ & $35.0(21)$ & $0.6(0.3-1.4)$ \\
\hline 12 months & $93.8(225)$ & $23.3(12.1-44.7)$ & $35.8(43)$ & $0.7(0.4-1.2)$ \\
\hline 24 months & $97.5(234)$ & $61.3(24.8-151.9)$ & $30.0(36)$ & $0.5(0.3-1.0)$ \\
\hline
\end{tabular}


Table 2: The compliance before, 6, 12, and 24 months after the implementation of clinical guidelines for depression in $\%$ (n). (Continued)

\begin{tabular}{|c|c|c|c|c|}
\hline \multicolumn{5}{|c|}{ Antidepressant medication } \\
\hline 0 months & $54.1(66)$ & reference & $45.9(28)$ & reference \\
\hline 6 months & $90.8(109)$ & $8.3(4.1-17.0)$ & $36.7(22)$ & $0.7(0.3-1.4)$ \\
\hline 12 months & $85.4(205)$ & $5.0(3.0-8.2)$ & $44.2(53)$ & $1.0(0.5-1.7)$ \\
\hline 24 months & $92.5(222)$ & $10.3(5.7-18.8)$ & $41.7(50)$ & $0.8(0.4-1.5)$ \\
\hline
\end{tabular}

na The numbers did not allow calculations.

Odds ratios adjusted for age and gender with baseline as the reference is presented with $\mathrm{Cl}$ (95\%)

change, at least over a two-year period, as documented by quality indicators. Our study describes the challenge implicit in real-world implementation aimed at improving the quality of care. The aim of all implementation is a change that remains after the support is withdrawn, and the results indicate that changes had taken place in the organization and structure of the care provided at the implementation clinics. In order to achieve these changes, an active implementation was needed and not just a dissemination of, or lecturing about, guidelines. This finding is in accord with earlier studies $[11,29,30]$.

It could be assumed that the current clinical practice was close to recommended care as presented in the guidelines, because the latter were based on information easily available to all clinicians. However, we found that there were large gaps between current clinical practice and recommended practice according to guidelines, especially in the clinics where guidelines for suicidal patients were implemented. The implementation required complex changes in clinical practice, better collaboration, and changes in the organization of care.

There are several likely explanations for the observed improvements. First, local implementation teams with multidisciplinary members were established. This initiative was intended to develop collaboration for organizational learning of best practice and change of clinical practice. The teams were encouraged to involve all staff at the clinic in adapting the guidelines for local use. Using local teams facilitated collaborative partnerships, integrated knowledge, and action. Thus, the team members gained a deeper understanding of the context and challenges of the local health service.

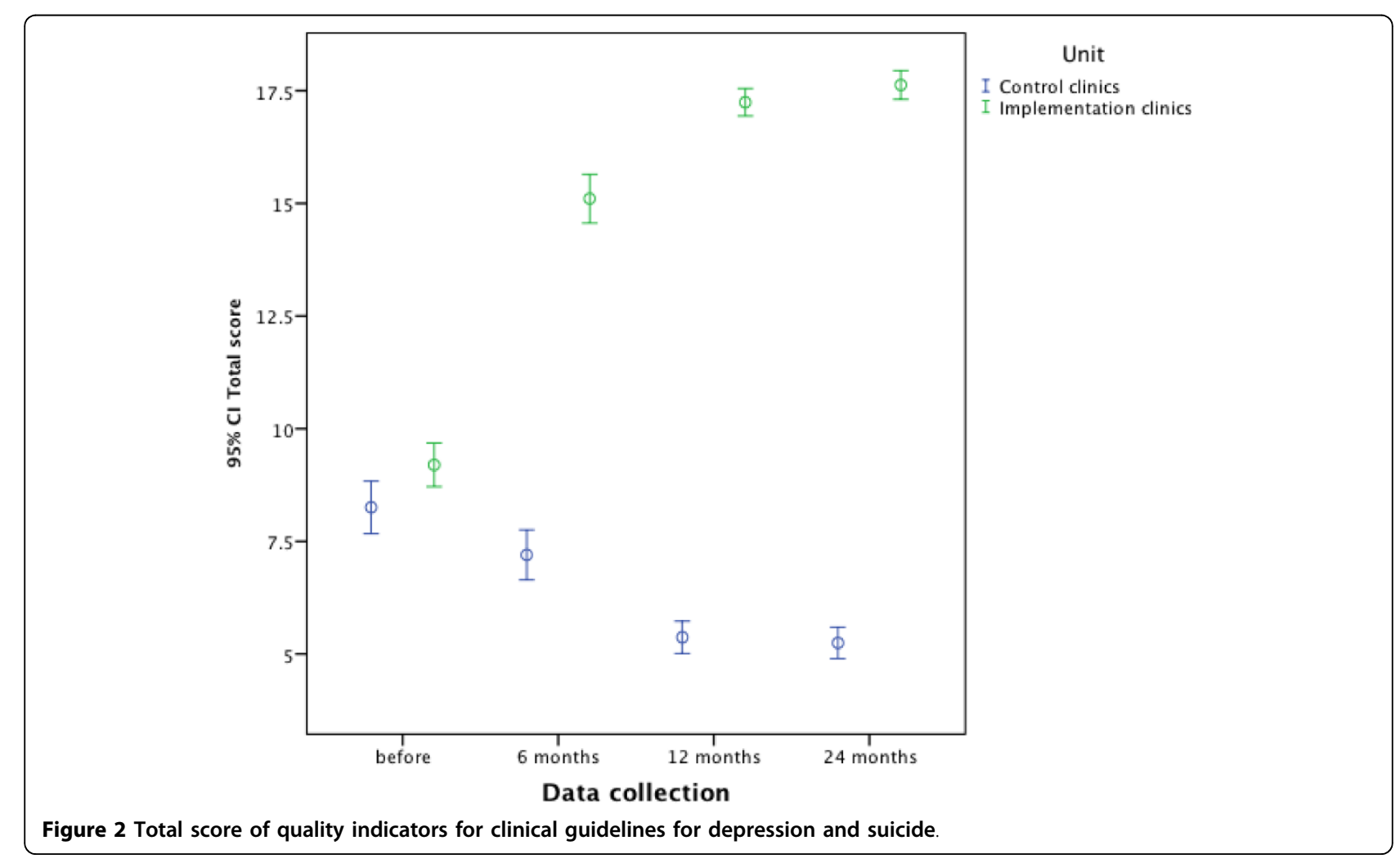


Table 3 The compliance before, 6, 12, and 24 months after the implementation of clinical guidelines for suicidal behaviour in $\%(\mathbf{n})$.

\begin{tabular}{|c|c|c|c|c|}
\hline \multirow[b]{2}{*}{ Indicator } & \multicolumn{2}{|c|}{ Implementation clinics } & \multicolumn{2}{|c|}{ Control clinics } \\
\hline & $\%(n)$ & OR $(95 \% \mathrm{Cl})$ & $\%(n)$ & OR $(95 \% \mathrm{Cl})$ \\
\hline \multicolumn{5}{|c|}{ Accessibility/wait time } \\
\hline 0 months & $15.7(19)$ & reference & $29.5(18)$ & reference \\
\hline 6 months & $14.2(17)$ & $0.9(0.4-1.8)$ & $31.7(19)$ & $1.1(0.5-2.4)$ \\
\hline 12 months & $70.4(169)$ & $13.7(7.7-24.4)$ & 0 & na \\
\hline 24 months & $59.2(142)$ & $8.3(4.7-14.6)$ & 0 & na \\
\hline \multicolumn{5}{|c|}{ Diagnostic assessment } \\
\hline 0 months & $49.6(60)$ & reference & $26.2(16)$ & reference \\
\hline 6 months & $73.3(88)$ & $2.9(1.7-5.0)$ & $16.7(10)$ & $0.6(0.2-1.5)$ \\
\hline 12 months & $83.3(200)$ & $5.4(3.2-8.9)$ & $0.8(1)$ & $0(0.0-0.2)$ \\
\hline 24 months & $91.7(220)$ & $11.8(6.5-21.2)$ & 0 & na \\
\hline \multicolumn{5}{|c|}{ Diagnostic instrument } \\
\hline 0 months & 0 & reference & 0 & reference \\
\hline 6 months & $7.5(9)$ & na & 0 & na \\
\hline 12 months & 0 & na & 0 & na \\
\hline 24 months & $7.5(18)$ & na & 0 & na \\
\hline \multicolumn{5}{|c|}{ Standardized rating scale } \\
\hline 0 months & $41.3(50)$ & reference & $27.9(17)$ & reference \\
\hline 6 months & $67.5(81)$ & $3.0(1.7-5.0)$ & $16.7(10)$ & $0.5(0.2-1.4)$ \\
\hline 12 months & $79.2(190)$ & $5.5(3.4-8.9)$ & 0 & na \\
\hline 24 months & $78.3(188)$ & $5.2(3.2-8.4)$ & $0.8(1)$ & $0.0(0.0-0.2)$ \\
\hline \multicolumn{5}{|c|}{ Standardized rating scale during treatment } \\
\hline 0 months & $16.5(20)$ & reference & $16.4(10)$ & reference \\
\hline 6 months & $52.5(63)$ & $5.8(3.2-10.5)$ & $10.0(6)$ & $0.6(0.2-1.7)$ \\
\hline 12 months & $22.9(55)$ & $1.6(0.9-2.7)$ & $0.8(1)$ & $0.04(0.02-0.35)$ \\
\hline 24 months & $55.8(134)$ & $6.6(3.8-11.3)$ & $5.0(6)$ & $0.3(0.1-0.9)$ \\
\hline \multicolumn{5}{|c|}{ Substance/drug abuse } \\
\hline 0 months & $52.1(63)$ & reference & $55.7(34)$ & reference \\
\hline 6 months & $64.2(77)$ & $1.7(1.0-2.9)$ & $56.7(34)$ & $1.0(0.5-2.1)$ \\
\hline 12 months & $77.5(186)$ & $3.4(2.1-5.5)$ & $25.0(30)$ & $0.3(0.2-0.5)$ \\
\hline 24 months & $80.0(192)$ & $3.8(2.4-6.2)$ & $29.2(35)$ & $0.3(0.1-0.6)$ \\
\hline \multicolumn{5}{|c|}{ Treatment (care) plan } \\
\hline 0 months & $37.4(68)$ & reference & $44.3(27)$ & reference \\
\hline 6 months & $58.9(106)$ & $4.4(2.5-7.6)$ & $41.7(25)$ & $0.9(0.4-1.9)$ \\
\hline 12 months & $67.1(161)$ & $4.4(2.7-7.1)$ & $0.8(1)$ & $0.0(0.0-0.1)$ \\
\hline 24 months & $79.2(190)$ & $8.0(4.9-13.3)$ & $0.8(1)$ & $0.0(0.0-0.1)$ \\
\hline \multicolumn{5}{|c|}{ Evaluation/outcome } \\
\hline 0 months & $20.7(25)$ & Reference & $19.7(12)$ & reference \\
\hline 6 months & $47.5(57)$ & $3.5(2.0-6.2)$ & $8.3(5)$ & $0.4(0.1-1.2)$ \\
\hline 12 months & $25.8(62)$ & $1.3(0.8-2.3)$ & 0 & na \\
\hline 24 months & $51.7(124)$ & $4.1(2.5-6.9)$ & 0 & na \\
\hline \multicolumn{5}{|l|}{ Continuity } \\
\hline 0 months & $86.0(104)$ & reference & $49.2(30)$ & reference \\
\hline 6 months & $81.7(98)$ & $0.7(0.4-1.5)$ & $31.7(19)$ & $0.5(0.2-1.1)$ \\
\hline 12 months & $96.3(231)$ & $4.2(1.8-9.9)$ & 0 & na \\
\hline 24 months & $91.3(219)$ & $1.7(0.9-3.5)$ & 0 & na \\
\hline \multicolumn{5}{|c|}{ Suicide assessment } \\
\hline 0 months & $55.4(67)$ & reference & $82.0(50)$ & reference \\
\hline 6 months & $93.3(112)$ & $13.6(5.9-31.5)$ & $73.3(44)$ & $0.6(0.2-1.4)$ \\
\hline 12 months & 87.1 (209) & $6.1(3.5-10.6)$ & $50.0(60)$ & $0.2(0.1-0.5)$ \\
\hline 24 months & 97.1 (233) & $33.6(14.1-80.2)$ & $56.7(68)$ & $0.3(0.1-0.6)$ \\
\hline
\end{tabular}




\begin{tabular}{|c|c|c|c|c|}
\hline \multicolumn{5}{|c|}{ Specialist assessment } \\
\hline 0 months & $50.4(61)$ & reference & $83.6(51)$ & reference \\
\hline 6 months & $85.4(103)$ & $6.5(3.4-12.3)$ & $83.3(50)$ & $1.0(0.4-2.6)$ \\
\hline 12 months & $87.5(210)$ & $7.5(4.4-12.9)$ & 86.7 104) & $1.3(0.5-3.0)$ \\
\hline 24 months & 91.7 (220) & $11.8(6.5-21.5)$ & $71.7(86)$ & $0.5(0.2-1.1)$ \\
\hline \multicolumn{5}{|l|}{ Follow-up } \\
\hline 0 months & $72.7(88)$ & reference & $75.4(46)$ & reference \\
\hline 6 months & $88.3(106)$ & $2.9(1.5-5.8)$ & $65.0(39)$ & $0.6(0.3-1.4)$ \\
\hline 12 months & $86.3(207)$ & $2.4(1.4-4.1)$ & $34.2(41)$ & $0.2(0.1-0.3)$ \\
\hline 24 months & $92.1(221)$ & $4.5(2.4-8.3)$ & $37.5(45)$ & $0.2(0.1-0.4)$ \\
\hline \multicolumn{5}{|c|}{ Evaluation assessment } \\
\hline 0 months & $32.2(39)$ & reference & $18.0(11)$ & reference \\
\hline 6 months & $64.2(77)$ & $4.0(2.3-6.9)$ & $13.3(8)$ & $0.6(0.2-1.6)$ \\
\hline 12 months & $63.8(153)$ & $3.8(2.4-6.1)$ & $6.7(8)$ & $0.3(0.1-0.8)$ \\
\hline 24 months & $75.0(180)$ & $6.8(4.2-11.2)$ & $10.8(13)$ & $0.4(0.2-1.1)$ \\
\hline
\end{tabular}

Odds ratios adjusted for age and gender with baseline as the reference is presented with $\mathrm{Cl}$ (95\%)

na The numbers did not allow calculations.

Further, the interventions included audits and regular feedback, which helped the local teams to monitor the implementation. The aim was that the local teams would be able to choose the most important areas for intervention and to measure success in terms of improved compliance to the guidelines and outcomes. Previous studies have reported that this enhances learning and facilitate translation of insight to daily work $[31,32]$. The organization should make use of the change process to implement changes of proven effectiveness regarding implementations strategies.

The feedback was based on quality indicators that were easy to use and showed a high inter-reliability. The indicators were all process indicators that had previously been the subject of discussion as to how to use them more effectively in mental health care, and they were not particularly controversial [33]. Furthermore, the changes are unlikely to be sustained if implementation does not include repeated measurements to access advancement and encourage modifications.

Another active strategy was that an outside researcher made regular visits to support the local teams. Moreover, all involved teams were part of a regional network that held regular meetings, because successful adoption of innovations often depends on interpersonal relationships within a system or an organization. An organization that supports knowledge sharing, and encourages observation and reflections is more successful at innovation and diffusion [34]. The network, as well as the visits, facilitated this. Although the teams worked locally, they were able to learn about organizational culture, implementation technique, and improvement models from colleagues in the regional network. Moreover, this supported the involved practitioners in analyzing, reflecting upon, and changing their own attitudes and behaviours. The goal was to transfer implementation technology into the participating organizations in order to continuously improve each organization's capacity for change.

Another critical issue for success of a diffusion of innovation strategy is leadership [35]. Leadership is described as an important factor in translating guidelines into clinical practice. Lack of support from leadership is identified as one of the greatest barriers [36]. According to Garside [37], leaders must continually show the desired direction of change, and support the staff in their new roles and new skills in a change of organisation or process. In the present study, the leadership was involved at an initial meeting at which the guidelines were presented. Because they had all volunteered to participate, they supported the implementation activities and created a culture in which the changes in clinical practice were possible.

Thus, a multifaceted intervention including a variety of active strategies was used [3], which previously has been reported to be more effective than passive strategies or just the use of feed-back or audit [38]. Shortell et al. [39] have suggested that five dimensions are needed for a successful implementation, i.e., process, strategic, cultural, technical, and structural. Our implementation program included all of these dimensions.

The standard of care is not the same as the quality of care. The quality of care provided by the clinician may be below, equal to, or even above the acceptable standard of care. Practice parameters are strategies for patient management, designed to assist health care professionals in clinical decision-making. The practice 
parameters describe the generally accepted practices, but are not intended to define a standard of care. The intentions with the quality indicators as presented in the clinical guidelines were to represent ideal practice. Thus, they could be used to measure deficiencies between current practice and ideal practice as defined in the guidelines, which would indicate an area for intervention. These practice parameters reflect the state of knowledge at the time of development of the guidelines, and most certainly need to be regularly updated.

Psychiatric disorders are of great importance in public health. Depression is now the fourth-leading cause of the global disease burden and the leading cause of disability worldwide. Depression is the most important risk factor for suicide, which is among the top three causes of death in young people ages 15 to 35 [40]. Depression seriously reduces the quality of life for individuals and their families, and often aggravates the outcome of other physical health problems. Because depression is highly treatable, and currently undertreated, it is an appropriate focus for improvement of the treatment by implementing available evidenced-based clinical guidelines. Guideline implementation studies in the care of psychiatric disorders are lacking, but a review by Weingartner of clinical guidelines in chronic medical diseases has stressed the importance of multifaceted interventions [41]. A comparable conclusion that multiple strategies seem to be most effective is presented in a systematic meta-review by Francke [16].

There were some limitations in the present study. Firstly, although both intervention and control clinics were randomly assigned, all had volunteered to participate, and therefore probably were more motivated to change. Secondly, given the fact that clinical practice change is a complex phenomenon dependent on local context, results from one particular setting can be generalised only with great caution [42].

Our study had a cluster design where patients were nested within their health care providers, and the health care providers were nested within their clinics. While the clustering at the provider level was properly addressed in our analyses, due to the low number of participating clinics it was not possible to fit a threelevel model. Therefore, we could not investigate the possible role of clinic level covariates, and the lack of controlling for autocorrelation within clinics might inflate somewhat the standard error of our estimates.

Addressing local needs when implementing clinical guidelines is important in closing the gap between research and practice. The need to adapt implementation efforts to local circumstances has been shown to be valuable [43]. Adequate funding is needed to train the staff in the intervention techniques, establish protocols, and support evaluation of the outcome. Further research is needed on practical frameworks to facilitate the implementation of intervention in mental health care settings.

A large number of factors determine whether or not implementation will be successful and all factors cannot be addressed within one theory or model of change. Further studies are needed to examine our implementation approach with reference to theories about the implementation of change. The strength of the present study is that it is, to our knowledge, the first one to assess the long-term effects of implementation of psychiatric guidelines.

\section{Conclusions}

This study suggested that the compliance to clinical guidelines, for treatment of depression and suicidal behaviour, was implemented and sustained over a twoyear period after an active implementation. Quality indicators were helpful tools in the implementation process as well as in the evaluation. Thus, supported local implementation based on local organisation theory may be a strategy for narrowing the gap between evidencebased care and current practice.

\section{Acknowledgements}

This research was supported by Stockholm County Council, Sweden.

\section{Author details}

${ }^{1}$ Department of Public Health Sciences, Karolinska Institutet, Stockholm, SE171 76, Sweden. ${ }^{2}$ Department of Clinical Neuroscience, Section of Psychiatry St Göran's Hospital, Karolinska Institutet, Stockholm, SE-112 81, Sweden. ${ }^{3}$ Medical Management Centre, Department of Learning, Informatics, Management, and Ethics, Karolinska Institutet, Stockholm, SE- 171 77, Sweden. ${ }^{4}$ Department of Public Health, University of Helsinki, Helsinki, Finland. ${ }^{5}$ Department of Public Health Sciences, Karolinska Institutet, Stockholm, SE-171 76, Sweden. ${ }^{6}$ Department of Epidemiology, Rio de Janeiro State University, Brazil.

\section{Authors' contributions}

$T F, A \AA W, M B$, and $Y F$ have all participated to the design of the study. TF, YF, $I J$, and APL have analyzed the data. All authors participated in interpretation of the results. TF drafted the manuscript and all other authors provided critical revision of the draft for important intellectual content. All authors read and approved the final manuscript.

\section{Competing interests}

The authors declare that they have no competing interests.

Received: 1 August 2008

Accepted: 26 January 2010 Published: 26 January 2010

\section{References}

1. Grol R, Grimshaw J: From best evidence to best practice: effective implementation of change in patients' care. Lancet 2003, 362:1225-1230.

2. Grimshaw JM, Thomas RE, MacLennan G, Fraser C, Ramsay CR, Vale L, Whitty P, Eccles MP, Matowe L, Shirran L, et al: Effectiveness and efficiency of guideline dissemination and implementation strategies. Health Technol Assess 2004, 8:iii-iv, 1-72.

3. Caminiti C, Scoditti U, Diodati F, Passalacqua R: How to promote, improve and test adherence to scientific evidence in clinical practice. BMC health services research 2005, 5:62.

4. Grimshaw JM, Eccles MP: Is evidence-based implementation of evidencebased care possible?. The Medical journal of Australia 2004, 180:550-51. 
5. Field M, Lohr KN: Guidelines for Clinical Practice: from Development To Use Washington, DC: National Academy Press 1992.

6. Gartlehner G, West SL, Lohr KN, Kahwati L, Johnson JG, Harris RP, Whitener L, Voisin CE, Sutton S: Assessing the need to update prevention guidelines: a comparison of two methods. Int I Qual Health Care 2004, 16:399-406.

7. Barosi G: Strategies for dissemination and implementation of guidelines. Neurol Sci 2006, 27(Suppl 3):S231-234.

8. Grol R: Successes and failures in the implementation of evidence-based guidelines for clinical practice. Medical care 2001, 39:||46-54.

9. Bero LA, Grilli R, Grimshaw JM, Harvey E, Oxman AD, Thomson MA: Closing the gap between research and practice: an overview of systematic reviews of interventions to promote the implementation of research findings. The Cochrane Effective Practice and Organization of Care Review Group. BMJ (Clinical research ed) 1998, 317:465-468.

10. Kingston ME, Krumberger JM, Peruzzi WT: Enhancing outcomes: guidelines, standards, and protocols. AACN Clin Issues 2000, 11:363-374.

11. Linden $M$, Westram A, Schmidt LG, Haag C: Impact of the WHO depression guideline on patient care by psychiatrists: a randomized controlled trial. Eur Psychiatry 2008, 23:403-408.

12. Davis D: Continuing education, guideline implementation, and the emerging transdisciplinary field of knowledge translation. J Contin Educ Health Prof 2006, 26:5-12

13. Schneider F, Harter M, Brand S, Sitta P, Menke R, Hammer-Filipiak U, Kudling R, Heindl A, Herold K, Frommberger U, et al: Adherence to guidelines for treatment of depression in in-patients. Br J Psychiatry 2005, 187:462-469.

14. Craig P, Dieppe P, Macintyre S, Michie S, Nazareth I, Petticrew M: Developing and evaluating complex interventions: the new Medical Research Council guidance. BMJ (Clinical research ed) 2008, 337:a1655.

15. Michie $\mathrm{S}$, Johnston $\mathrm{M}$ : Changing clinical behaviour by making guidelines specific. BMJ (Clinical research ed 2004, 328:343-345.

16. Francke AL, Smit MC, de Veer AJ, Mistiaen P: Factors influencing the implementation of clinical guidelines for health care professionals: a systematic meta-review. BMC Med Inform Decis Mak 2008, 8:38.

17. Campbell SM, Braspenning J, Hutchinson A, Marshall M: Research methods used in developing and applying quality indicators in primary care. Quality \& safety in health care 2002, 11:358-364.

18. Nietert PJ, Wessell AM, Jenkins RG, Feifer C, Nemeth LS, Ornstein SM: Using a summary measure for multiple quality indicators in primary care: the Summary QUality InDex (SQUID). Implement Sci 2007, 2:11

19. Weinmann $S$, Koesters $M$, Becker T: Effects of implementation of psychiatric guidelines on provider performance and patient outcome: systematic review. Acta Psychiatr Scand 2007, 115:420-433.

20. Medicinskt programarbete: Regionalt vårdprogram. Vård av suicidnära patienter Stockholm County Council 2002.

21. Medicinskt programarbete: Regionalt vårdprogram för depressionssjukdomar inkl. mano-depressiv sjukdom Stockholm: Stockholm County Council, First 2003.

22. Forsner T, Aberg Wistedt A, Brommels M, Forsell Y: An approach to measure compliance to clinical guidelines in psychiatric care. $B M C$ Psychiatry 2008, 8:64

23. Cleghorn GD, Headrick LA: The PDSA cycle at the core of learning in health professions education. Jt Comm J Qual Improv 1996, 22:206-212

24. Garvin D: Learning in action: a guide to putting the learning organization to work Boston: Harvard Business School Press 2000.

25. World Health Organization: International statistical classification of diseases and related health problems, Tenth Revision Geneva, Switzerland: World Health Organization, Second 2004.

26. American Psychiatric Association: Diagnostic and statistical manual of mental disorders Washington, DC American Psychiatric Press, Fourth 1994

27. Nordstrom G, Gardulf A: Nursing documentation in patient records. Scand J Caring Sci 1996, 10:27-33.

28. Rabe-Hesketh S, Skrondal A: Multilevel and Longitudinal Modeling Using Stata College Station, Tex:: StataPress, 22008.

29. Linden $M$, Schotte $K$ : A randomized controlled clinical trial comparing "guideline exposed" and "guideline naive" physicians in respect to dosage selection and treatment outcome with doxepin in depressive disorders. Pharmacopsychiatry 2007, 40:77-81.

30. Thompson C, Kinmonth AL, Stevens L, Peveler RC, Stevens A, Ostler KJ, Pickering RM, Baker NG, Henson A, Preece J, et al: Effects of a clinical- practice guideline and practice-based education on detection and outcome of depression in primary care: Hampshire Depression Project randomised controlled trial. Lancet 2000, 355:185-191.

31. Rushmer RK, Kelly D, Lough M, Wilkinson JE, Greig GJ, Davies HT: The Learning Practice Inventory: diagnosing and developing Learning Practices in the UK. Journal of evaluation in clinical practice 2007, 13:206-211.

32. Eijkelberg IM, Spreeuwenberg C, Mur-Veeman IM, Wolffenbuttel BH: From shared care to disease management: key-influencing factors. International journal of integrated care 2001, 1:e17.

33. Hermann RC, Palmer RH: Common ground: a framework for selecting core quality measures for mental health and substance abuse care. Psychiatric services (Washington, DC) 2002, 53:281-287.

34. Holsapple CW: Handbook on knowledge management 1: Knowledge matters Berlin: Springer 2004

35. Plsek PE, Greenhalgh T: Complexity science: The challenge of complexity in health care. BMJ (Clinical research ed) 2001, 323:625-628.

36. Gifford WA, Davies B, Graham ID, Lefebre N, Tourangeau A, Woodend K: A mixed methods pilot study with a cluster randomized control trial to evaluate the impact of a leadership intervention on guideline implementation in home care nursing. Implement Sci 2008, 3:51.

37. Garside P: Organisational context for quality: lessons from the fields of organisational development and change management. Qual Health Care 1998, 7(Suppl):S8-15.

38. Shojania KG, Grimshaw JM: Evidence-based quality improvement: the state of the science. Health affairs (Project Hope) 2005, 24:138-150.

39. Shortell SM, Bennett CL, Byck GR: Assessing the impact of continuous quality improvement on clinical practice: what it will take to accelerate progress. The Milbank quarterly 1998, 76:593-624, 510.

40. Murray CJ, Lopez AD: Global mortality, disability, and the contribution of risk factors: Global Burden of Disease Study. Lancet 1997, 349:1436-1442.

41. Weingarten SR, Henning JM, Badamgarav E, Knight K, Hasselblad V, Gano A $\mathrm{Jr}$, Ofman JJ: Interventions used in disease management programmes for patients with chronic illness-which ones work? Meta-analysis of published reports. BMJ (Clinical research ed) 2002, 325:925.

42. Greenhalgh T, Robert G, Macfarlane F, Bate P, Kyriakidou O: Diffusion of innovations in service organizations: systematic review and recommendations. The Milbank quarterly 2004, 82:581-629.

43. Kochevar LK, Yano EM: Understanding health care organization needs and context. Beyond performance gaps. J Gen Intern Med 2006, 21(Suppl 2):S25-29.

\section{doi:10.1186/1748-5908-5-4}

Cite this article as: Forsner et al: Supported local implementation of clinical guidelines in psychiatry: a two-year follow-up. Implementation Science 2010 5:4

\section{Submit your next manuscript to BioMed Central and take full advantage of:}

- Convenient online submission

- Thorough peer review

- No space constraints or color figure charges

- Immediate publication on acceptance

- Inclusion in PubMed, CAS, Scopus and Google Scholar

- Research which is freely available for redistribution
C Biomed Central 